\title{
GRADO DEL MODIFICADOR NOMINAL Y LA VARIACIÓN DEL ARTÍCULO EN ESPAÑOL
}

\author{
Janusz Pawlik \\ Universidad A. Mickiewicz, Poznań \\ http://dx.doi.org/10.18778/8220-201-4.24
}

\section{Resumen}

Al estudiar la teoria y práctica del artículo español sería recomendable examinar con detalle la relación entre el adjetivo calificativo y la alternancia del artículo como determinante del grupo nominal. En la presente comunicación se pretende pasar revista a algunas estructuras comparativas y superlativas que inciden decisivamente sobre una forma concreta del determinante. Entre ellas cabe señalar las construcciones de relativo y otras dos construcciones superlativas que prescinden del artículo definido junto al grupo cuantificativo.

Palabras clave: Artículo español, construcción superlativa de relativo, grupo cuantificativo, comparativos sincréticos.

\section{1.}

\section{El grado de un modificador y la referencia del GN}

El propósito de esta contribución es revisar la variación del artículo en las llamadas construcciones superlativas. Los ejemplos de base que nos introducen en el tema son muy claros:

(1) Ahora, el Conservatorio de Madrid no es el mejor sitio para estudiar guitarra. [superlativo relativo]

(2) ¿Todavía no has encontrado un sitio mejor para esconderte? [comparativo] 
Es sabido que el artículo indefinido imprime al adjetivo de un GN la lectura del grado comparativo1. El artículo definido, en cambio, está estrechamente asociado a la interpretación del grupo cuantificativo en su grado extremo (superlativo relativo). Es un principio generalizado en buena parte de lenguas con artículo (a more important problem / the most important problem) y el castellano no se aparta de esta solución referencial. El grado máximo de alguna propiedad que caracteriza al sustantivo es compatible también con los posesivos (sus territorios más desarrollados) (Leonetti, 2016: 537).

Lyons (1999: 246) apunta que el superlativo va con la marca de definitud en todas las lenguas con artículos (the cleverest boy, *a cleverest boy). Salvo los posesivos, el autor inglés excluye otros determinantes de esta posición afirmando que "In fact not only are strong determiners like all, most, and cardinal determiners like some in their quantificational use, excluded with superlatives ( ${ }^{*}$ all/every/most/some/many cleverest boy $(s)$ ), but so too are demonstratives ( ${ }^{\star}$ that cleverest boy)". Hawkins (1978: 235), por su parte, explica por qué los superlativos requieren invariablemente un determinante definido: "a uniqueness or inclusiveness element in their meaning accounts for the definiteness effect they display. Superlativeness means having some property to an extent to which no other objects have it: Sarah was the prettiest girl at the party".

Los superlativos relativos pueden contar con un complemento restrictivo ${ }^{2}$ que designa el dominio con respecto al cual se predica la propiedad en su grado máximo: el mejor libro de estos veinte / el atleta que ha cosechado más victorias del campeonato (MNGLE, 2010: 872). Otra cuestión que se plantea es la ambigüedad de los adverbios cuantificadores más y menos que no conllevan, como en otras lenguas, diferencias morfológicas para distinguir el grado comparativo del superlativo, p. ej.:

(3) estudiar más que el resto de la clase. 'study more than the rest of the class' pol. 'uczyć się więcej niż reszta klasy'

$1 \mathrm{O}$, mejor dicho, es el grado quien incide en el determinante.

2 Los superlativos con este tipo de coda se llaman en Bello (1847) 'partitivos'. 
(4) estudiar más de toda la clase.

'study the most of all the class'

pol. 'uczyć się najwięcej z całej klasy'

Si se omiten los complementos restrictivos (que el resto de la clase y de toda la clase), la frase se vuelve ambigua. Es de notar que ambos términos de referencia se admiten en la construcción de relativo el alumno que ha estudiado más. Con todo, en la variante sin coda, se suele entender por defecto el cuantificador como relativo a la totalidad de los elementos que componen el grupo restrictivo, es decir, el alumno que ha estudiado más \{de toda la clase\} (MNGLE, 2010: 873).

Brucart (1999: 480) afirma que una de las diferencias que media entre las construcciones comparativas y superlativas atañe a la posibilidad de colocar el sintagma cuantificativo delante del verbo. Esta posibilidad está solo al alcance de los GN superlativos:

(5) El aspirante que más puntos obtuvo \{de todos\} fue Luis.

${ }^{\star}$ El aspirante que más puntos obtuvo que María fue Luis.

\section{2.}

\section{La llamada 'construcción superlativa de relativo'}

El grado extremo en una cláusula de relativo no afecta solo a adverbios de cantidad (más, menos). El cuantificador de las construcciones superlativas puede incidir también sobre un adjetivo graduable (el más rico $)^{3}$, pero también sobre un sustantivo (el que tiene más dinero) (Alarcos, 1994: 86; NGLE, 2009: 3433). Así, las construcciones superlativas pueden ser SIMPLES, como el edi-

3 En el corpus de Mark Davies se documentan sobre todo ejemplos que siguen el patrón NOMBRE que VERBO (SEMI)COPULATIVO más ADJETIVO, p. ej. ¿Cuál es el personaje que considera más despreciable de la historia? 
ficio más alto, o bien COMPLEJAS o DE RELATIVO, como la habitación que tiene más camas \{de todo el albergue\}. Las primeras llevan artículo o posesivo, las segundas no. Dice MNGLE (2010: 873) que

No son construcciones superlativas complejas las que contienen superlativas simples en oraciones subordinadas, como $\underline{e l}$ actor de cine que nos parecía el más atractivo, donde la presencia del artículo $e l$ marca la diferencia con la superlativa compleja el actor de cine que nos parecía más atractivo.

Esta última se caracteriza por que el rasgo que aporta el $\mathrm{AD}$ (esencial en la construcción superlativa) aparece fuera de la oración de relativo, por tanto a distancia del grupo cuantificativo.

El concepto de 'construcción superlativa compleja' aparece por vez primera en la NGLE (2009). Antes la problemática de los superlativos en una cláusula relativa fue abordada esporádicamente, entre otros, por Bosque y Brucart (1991), Brucart (1999) y Sáez del Álamo (1999). Ninguna gramática española anterior a esta fecha da cuenta de tales estructuras (véase Alcina, Blecua, 1975; Hernández, 1986; Esbozo, 1973).

Es sabido que los grupos cuantificativos con más menos y con los comparativos sincréticos mejor peor/mayor menor no se muestran capaces de distinguir morfológicamente la gradación de sus propiedades. Por lo tanto, las construcciones superlativas de relativo sirven para prestar a un sustantivo una propiedad en su máxima intensidad:

(6) Vi a los artistas que han pintado mejores cuadros.

(7) Son las que presentan mayor incremento este año.

Las estructuras subrayadas hacen eco de otra que sirve para expresar adverbios en su grado extremo. Veamos un par de ejemplos oportunos:

(8) Es la persona que conoce mejor los entresijos de la UE.

(9) Hemos comprado los libros que más se han vendido este año.

(10) Visitamos a la amiga que vive más cerca. 
En los ejemplos transcritos, se puede apreciar que los adverbios superlativos van sin determinante y no se distinguen en nada de su grado comparativo. La misma construcción de relativo la podemos observar en la gradación de adverbios modales (con más/ menos), no siempre bien asimilada por estudiantes polacos de español como segunda lengua, p. ej.:

(11) Mario habla más alto \{que Daniel y Pablo\}.

(12) Gabriel es el que (o quien) habla más alto (o más alto habla) \{de todos\} $\}^{4}$.

En total, dichas estructuras de relativo se ven apropiadas para expresar el grado máximo de una propiedad o cantidad asignada al verbo o al nombre mediante los cuantificadores (más, menos) y comparativos sincréticos (mejor, peor / mayor, menor). Tales grupos pueden cumplir diversas funciones sintácticas dentro de una oración (cf. Brucart, 1999: 479), como puede verse en:

(13) El deporte que genera más entusiastas [CD] en el mundo sigue siendo el fútbol.

(14) La mejor noticia es la que interesa a más lectores [CI].

(15) Este es el procedimiento que inconscientemente utilizamos con mayor frecuencia [CC].

Es muy llamativo que en este tipo de oraciones aparezca siempre un argumento (o un adjunto) ${ }^{5}$ de carácter definido (el deporte, $\underline{\text { la }}$ mejor noticia, el procedimiento), localizado en la cláusula principal, a pesar de que el grupo nominal de control va en la subordinada:

(16) El deporte [que] genera más entusiastas en el mundo.

(17) El deporte [que] más entusiastas genera en el mundo.

El condicionante decisivo de tal construcción es el nexo que sin el cual el grado del GN estudiado debería interpretarse como comparativo:

4 Por supuesto, hacemos abstracción del superlativo con artículo lo, p. ej. Grité lo más fuerte que pude.

5 Como en La empresa en la que más tiempo he trabajado. 
(18) El deporte genera más entusiastas en el mundo.

(19) La palabra experimenta más variaciones.

No se puede olvidar el carácter preferentemente copulativo de toda la oración compuesta dentro de la cual la construcción estudiada ejerce el oficio de atributo:

(20) El verbo es la palabra que más variaciones experimenta. [=el verbo lo es]

(21) González es la persona que conoce mejor los entresijos de la UE. [=González lo es $]^{6}$

En todo caso, son viables asimismo estructuras con predicado verbal como Vi a los artistas que han pintado mejores cuadros (Bosque, Brucart, 1991: 18).

El empleo de una construcción superlativa de relativo no está exento de limitaciones. De momento, vale la pena hacer notar un importante obstáculo que impide su uso. Considérese la frase El cantante que ha grabado el mejor disco que no puede prescindir del $\mathrm{AD}$ en el superlativo simple el mejor disco. Por lo tanto, para expresar el grado máximo no se puede recurrir a una construcción compuesta sin artículo, como lo hemos observado en ejemplos anteriores. Esta es una importante restricción que se impone al núcleo contable disco. No obstante, se admiten grupos escuetos que inciden sobre nombres plurales (Juan es el chico que mejores libros compró) y nombres no contables (los precios que presentan mayor incremento este año).

El análisis de tales ejemplos comprueba la existencia de construcciones superlativas simples (Juan es el chico que comprólos $\underline{\text { mejores libros) }})^{7}$ que compiten con las compuestas (Juan es el chico que compró mejores libros). La alternancia de superlativos simples y compuestos en una cláusula relativa es un tema poco explorado hasta el momento y merece un estudio más detenido, pero no es objeto de la presente elaboración.

6 Un test de pronominalización comprueba claramente la repartición de las funciones en una construcción superlativa de relativo.

7 Sorprende que sean agramaticales los grupos simples con anteposición: *Juan es el chico que los mejores libros compró (Sáez del Álamo, 1999: 1181). 


\section{Otras construcciones nominales graduables}

Ahora pasamos a presentar otra estructura sintáctica, sin oración relativa, capaz de desambiguar la molesta igualdad formal de los dos grados. Los grupos preposicionales encabezados por con, empleados en función de adjuntos nominales [NOMBRE1+con+ADJ+NOMBRE2], encierran a veces los comparativos mayor, menor I mejor, peor o los cuantificadores más, menos. El estudio de los múltiples ejemplos recogidos en el corpus CREA y de Mark Davies llega a confirmar la tesis de que el grupo cuantificativo escueto se definirá como superlativo, siempre y cuando el núcleo nominal precedente (NOMBRE1) se acompañe de un AD:

(22) El legislador debería comenzar por las sustancias con mayores índices reales de consumo.

(23) Se trata de la institución con mayor transparencia en las decisiones.

(24) Se ha abandonado siempre, tal vez, el grupo humano con más necesidades, con más angustias que es lo que yo llamo el peón con tierra.

(25) La gran aventura de Mortadelo y Filemón es la película española con mejor entrada en la historia del cine español.

Los ejemplos aducidos contrastan nítidamente con los que comprenden GNs indefinidos, en que los mismos adjuntos admiten la interpretación opuesta:

(26) Estamos proyectando una política exterior con mayor autonomía.

(27) Las reducidas exigencias ambientales de China ponen a su productor en ventaja competitiva frente a los otros productores de países con más estrictos estándares ambientales.

La misma regla puede detectarse en los segmentos introducidos por la preposición de que desempeñan el papel de adjuntos clasificativos: 
(28) Intentaría una política exterior de mayor afirmación nacional.

(29) Los arrendatarios deben abandonarla forzosamente, siendo reubicados en una nueva tierra de peor calidad, menos accesible y de secano.

(30) El Observatorio del Teide conseguirá imágenes de mejor calidad que "Boomerang".

Conforme a lo dicho anteriormente, con un AD inicial del grupo asistimos a un cambio de grado, de comparativo a superlativo:

(31) En el pueblo de menor natalidad, dicha tasa es de 2,05 yen el de mayor de 10,79.

(32) El diplodoco es quizá el reptil de mayor tamaño que ha existido en la Tierra ${ }^{8}$.

(33) El equipo de peor campaña a domicilio fue Santa Fe, que empató cuatro partidos y perdió dos.

\section{4. \\ Dos segmentos superlativos rivales de un grupo preposicional}

En su aplastante mayoría tales grupos superlativos no van precedidos de actualizador, si bien se reconocen como gramaticales también los sintagmas con AD. En el corpus de Mark Davies hemos calculado la proporción de incidencia de ambos segmentos competidores en algunas estructuras. Por ejemplo, la expresión [el país con (el) mayor número de] aparece 689 veces sin actualizador frente a 372 con el $\mathrm{AD}$, como puede apreciarse en:

(34) EE.UU será el país con mayor número de hispanohablantes del mundo en 2060.

8 El ejemplo viene del Esbozo (1973: 420), la primera publicación en mencionar tal estructura. 
(35) España es el país con el mayor número de bares y restaurantes a nivel mundial.

La predominancia del segmento escueto se perfila con más claridad en la pauta [los NOMBRE con (la) menor NOMBRE] que arroja una proporción de 1746 a 106:

(36) San Isidro es hoy uno de los distritos con menor incidencia delictiva de la capital.

(37) Por otro lado, los bancos con la menor cartera de créditos son Procredit, Banco Multibanky Banco Santander.

La estructura [el NOMBRE de más ADJETIVO NOMBRE] registra una incidencia de 1063 ocurrencias respecto a 396 ejemplos con el determinante:

(38) El hombre de más baja estatura del mundo, el nepalés Chandra Bahadur, falleció en las islas de Samoa de Estados Unidos.

(39) Este discurso provocó el inicio de la más grave crisis en la segunda mitad del pasado siglo9.

Siendo así, cabe considerar la primera construcción superlativa como la primordial en castellano. Con todo, es la coda quien esclarece en última instancia el grado comparativo o superlativo que se asigna a la expresión nominal. La segunda variante, más esporádica y a primera vista redundante, sirve en contextos ambiguos para poner de manifiesto el carácter extremo de la propiedad aludida.

Al revés que las construcciones de relativo, estas admiten con más amplitud la gradación del adjetivo de forma analítica, p. ej. Somos uno de los países con más altos niveles de depresión en el mundo; Es el país de más rápido desarrollo económico en el mundo (cf. Kany 1963: 96).

9 La expresión con $\mathrm{AD}$ representa en general otro tipo de modificación nominal (adjunto de pertenencia). 


\section{5.}

\section{Construcciones superlativas en español y polaco}

Existen en ambas lenguas algunos casos contrarios, ambiguos o fronterizos en el empleo de los superlativos que merecen una reflexión más detenida. Si estamos manejando dos entidades cuyas características se sometan a comparación y estas entidades forman un conjunto de solo dos elementos, la selección del grado que preferentemente se adscribe a cada referente es distinta en español y en polaco:

(40) El más fuerte vencería al más débil. [superlativo] 'Silniejszy pokona stabszego'. [comparativo]

(41) En todas partes, entre las personas ancianas, las más pobres son las mujeres. [superlativo] 'Wszędzie, wśród ludzi starszych, biedniejsze są kobiety'. [compar.]

El grado superlativo del adjetivo en español corresponde en este caso al comparativo, que es de obligado uso, en la lengua polaca. Pero es necesario que se cumpla el requisito citado. Tenemos que ver un conjunto compuesto de dos elementos que tomamos en consideración: solo dos individuos (uno más fuerte que otro) o dos grupos naturales de personas (los hombres y las mujeres; estas más pobres que aquellos). Tienen que recordar esta divergencia los alumnos de ambas lenguas como lengua segunda.

En el caso revisado, es de señalar además el carácter sustantivado del adjetivo que aparece graduado. De modo que, en la frase el más fuerte, el AD designa en mayor medida la sustantivación del adjetivo fuerte que la marca de su máximo grado de intensidad. En rigor, existe la posibilidad de expresar el valor comparativo a través de un AI, p. ej. uno más fuerte vencería a otro más débil, pero en general no se practica. Otro tanto sucede con Nos dejamos engañar por los ricos / los más ricos donde los adjetivos nominalizados en plural, sean en grado positivo o en común a comparativo y superlativo, han de llevar obligatoriamente una marca de cambio de categoría los. Por lo tanto, el GN los más ricos se muestra a menudo como portador de comparación (Barbaud 1976: 137). 
La totalidad de dos constituyentes nominales se puede construir también de forma ocasional, lo que comprueba el ejemplo siguiente:

(42) En los casos graves se produce gran pérdida de líquidos... En los casos menos graves se producen diarreas leves, frecuentes sobre todo en turistas.

Según la intención del hablante, se efectúa supra una partición de los casos de la enfermedad comentada en los graves y los menos graves, tertium non datum [otra solución estando excluida]. Surgen así dos entidades (plurales) de una totalidad bimembre. El polaco recurre en tal caso naturalmente al grado comparativo (categoría no marcada): przypadki mniej poważne. En este contexto se utilizan asimismo GNs escuetos, es decir, en casos menos graves, por lo que se lleva a cabo un reparto en grupos menos tajante que antes, resaltando no un conjunto entero de unidades (los casos menos graves) sino unidades separadas, sueltas y no opuestas explícitamente a algún conglomerado compacto de entidades (los casos más graves):

(43) En casos menos graves se producen diarreas leves, frecuentes sobre todo en turistas.

Los casos de enfermedad a que nos referimos no tienen que representar necesariamente la totalidad de los casos considerados como 'menos graves', sino algunos selectos.

\section{6. \\ Observación final}

Hasta ahora hemos averiguado que la falta de AD no excluye la lectura superlativa del grupo cuantificativo. Al revés, puede ocurrir una situación opuesta. Es cuando se percibe una discordancia entre la forma morfológica propia del superlativo y el valor contextual comparativo de los adjetivos estudiados, como puede observarse en: 
(44) Cada país soporta las consecuencias de la calidad mayor o menor de los controles que pone en marcha en sus fronteras exteriores.

El operador la está justificado aquí más por el carácter identificable del segmento [la calidad mayor o menor], delimitado explícitamente por el adjunto preposicional de los controles..., que por la propiedad extrema que alcanza el calificador. En efecto, la definitud del GN llega a predominar en tales casos sobre el concepto de gradación. La confluencia de las dos funciones gramaticales que se observa en un significante (la) conduce invariablemente a la cancelación de una de ellas. ${ }^{10}$ Un ejemplo aun más llamativo de esta confusión será:

(45) Los restaurantes más caros que los del centro no deberían existir

en que la definitud del GN sujeto oracional viene a coincidir con la marca de su grado superlativo que por ello queda anulado. De hecho se habla de unos restaurantes más caros. Igual ocurre en El estudiante más listo que el profesor, donde, además, se pone de manifiesto la unicidad del referente estudiante (Bosque, Brucart, 1991: 13).

\section{Referencias bibliográficas}

Alarcos Llorach, E. (1994), Gramática de la lengua española, Madrid: Espasa Calpe.

Alcina Franch, J., Blecua, J. M. (1975), Gramática española, Barcelona: Ariel.

Barbaud, P. (1976), “Constructions Superlatives et Structures Apparentées”, Linguistic Analysis, 2, 125-174.

Bello, A. (1847), Gramática de la lengua castellana destinada al uso de los americanos, Santiago de Chile: Imprenta del Progreso. Bosque, I., Brucart, J. M. (1991), “QP raising in Spanish Superlatives”, texto multicopiado, UCM/UAB.

10 Es bien sabido que algunos complementos de un GN proporcionan el vínculo adecuado con el dominio de definitud, de modo que se cumple el requisito de unicidad necesario para realizar la identificación de una entidad designada (MNGLE, 2010: 268). 
Brucart, J. M. (1999), "La estructura del sintagma nominal: las oraciones de relativo", en I. Bosque y V. Demonte (eds.), Gramática descriptiva de la lengua española, Vol. 1, Madrid: Espasa-Calpe, 395-522.

(Esbozo) Real Academia Española (1973), Esbozo de una nueva gramática de la lengua española, Madrid: Espasa-Calpe.

Hawkins, J. (1978), Definiteness and Indefiniteness. A study in Reference and Grammaticality Prediction, London: Croom Helm.

Hernández, C. (1986), Gramática funcional del español, Madrid: Gredos.

Kany, C. E. (1963), American-Spanish Syntax, Chicago: University of Chicago Press.

Leonetti, M. (2016), “Determinantes y artículos”, en J. Gutiérrez-Rexach (ed.), Enciclopedia Lingüística Hispánica, Routledge, 532-543.

Lyons, C. (1999), Definiteness, Cambridge: Cambridge University Press.

(MNGLE) Real Academia Española y Asociación de Academias de la Lengua Española (2010), Nueva gramática de la lengua española. Manual, Madrid: Espasa Libros.

(NGLE) Real Academia Española y Asociación de Academias de la Lengua Española (2009), Nueva gramática de la lengua española, Madrid: Espasa Libros.

Sáez del Álamo, L. A. (1999), "Los cuantificadores: las construcciones comparativas y superlativas”, en I. Bosque, V. Demonte (eds.), Gramática descriptiva de la lengua española, Vol. 1, Madrid: Espasa-Calpe, 1129-1188.

\section{Fuentes de datos}

Davies, M., Corpus del español, [en línea] <https://www.corpusdelespanol/now $>$, [fecha de consulta: 12.02.2018].

Real Academia Española: Corpus de referencia del español actual (CREA), [en línea] <corpus.rae.es./creanet.html >, [fecha de consulta: 13.02.2018]. 